\title{
A comparison of the biological activities of ethyl acetate fractions from the stems and leaves of Penthorum chinense Pursh
}

\author{
Zhaolei WANG $^{1 *}$, Kai JIANG ${ }^{*}$, Qinchao DING ${ }^{1}$, Shujun LIU $^{2}$, Xiaobing DOU ${ }^{1}$, Bin DING (凶) ${ }^{1}$ \\ 1 College of Life Science, Zhejiang Chinese Medical University, Hangzhou 310053, China \\ 2 Beijing Stomatological Hospital/School of Stomatology, Capital Medical University, Beijing 100050, China
}

\begin{abstract}
Penthorum chinense Pursh (PCP) is a popular traditional medicinal plant in China, widely used for the treatment of a variety of liver diseases. Although it has been long recognized that the main active elements of PCP are contained in ethyl acetate fraction (EAF), little is known so far in terms of the relative effectiveness of EAF derived from the stems versus leaves of this plant. In the current study, we prepared EAF by reflux extraction and sequential extraction from the stems (SEAF) and leaves (LEAF) of PCP and tested their hepatoprotective efficacies. The extract rates and flavonoid contents of LEAF were higher than those of SEAF. EAFs $\left(>50 \mu \mathrm{g} \cdot \mathrm{mL}^{-1}\right)$ prevented lipid accumulation in cells and protected against lipotoxicity injury when the concentration exceeded $25 \mu \mathrm{g} \cdot \mathrm{mL}^{-1}$. More than $95 \%$ free radicals released by 2,2-diphenyl-1-picrylhydrazyl (DPPH) were eliminated by $25 \mu \mathrm{g} \cdot \mathrm{mL}^{-1} \mathrm{SEAF}$ and $50 \mu \mathrm{g} \cdot \mathrm{mL}^{-1} \mathrm{LEAF}$, respectively. Further, EAFs $\left(25 \mu \mathrm{g} \cdot \mathrm{mL}^{-1}\right)$ also showed protective antioxidant effects, with the activity of LEAF being significantly higher than that of SEAF. EAFs $\left(10 \mathrm{mg} \cdot \mathrm{mL}^{-1}\right)$ also showed similar unspecific bacteriostatic activity. In comparison with SEAF, LEAF contained more flavonoids and had a higher anti-oxidation capability and for these reasons we suggest it should be better for clinical use.
\end{abstract}

Keywords antibacterial, anti-oxidation, lipid accumulation, lipotoxicity, Penthorum chinense Pursh

\section{Introduction}

Liver is the most vital metabolic organ in vertebrates. Nutritional imbalance or ingestion of toxicity elements

Received March 12, 2019; accepted May 5, 2019

Correspondence: db@zcmu.edu.cn

${ }^{*}$ These authors contribute equally to the work causes dysfunction of hepatocytes, which influences energy balance, with the resulting energy surplus being stored as lipid droplets throughout the body, especially in the liver ${ }^{[1]}$. The hepatic capacity to oxidize, store and export free fatty acids (FFAs) as triglycerides (TGs) is overwhelmed by their flux from the periphery or hepatic $d e$ novo lipogenesis and the excess FFAs in liver may cause lipotoxicity ${ }^{[2,3]}$. This is a vicious cycle that, if left untreated, leads to nonalcoholic fatty liver disease (NAFLD), cirrhosis, and even hepatomas ${ }^{[4]}$. The mechanism which leads to lipid accumulation and nonalcoholic fatty liver disease (NAFLD) is largely unknown. Currently, oxidative stress (OS) is recognized to be one of the most important factors ${ }^{[5,6]}$, as well as intestinal flora released lipopolysaccharides (LPS ${ }^{[7,8]}$.

To date, no specific drug treatment exists for nonalcoholic fatty liver disease. Herbal tea has become increasingly popular and is associated with enhanced liver health. Ganhuangcao (Saxifragaceae, Penthorum chinense Pursh (PCP)) is a major medicinal plant in the Gulin District of Sichuan Province, China. It is also known as immortal grass' by Miao people, who have consumed this plant since ancient times ${ }^{[9]}$ and who believe that drinking PCP tea can protect against liver damage ${ }^{[10]}$. For decades, the curative effect of PCP has been explored on liver disease treatment in clinic, including hepatitis B-induced liver fibrosis ${ }^{[11-13]}$, alcoholic fatty liver caused by long-term drinking ${ }^{[14]}$, nonalcoholic steatohepatitis ${ }^{[15]}$, and cirrhosis ${ }^{[16]}$. Fundamental research on the active ingredients of PCP and their biological activities is ongoing. Some studies demonstrated that the main active elements are contained in the ethyl acetate fraction (EAF) from $\mathrm{PCP}^{[17-19]}$, such as anti-bacteria (bacteriostatic) activity ${ }^{[20,21]}$ and anti-oxidation activity ${ }^{[22]}$. It is common to separate the leaves from the stems of PCP when making tea ${ }^{[9,23,24]}$; however, the reasons for this are unclear. Therefore, in the current study, we compared and contrasted the biological activities of EAF in $70 \%$ ethanol extracts of PCP stems and leaves. 


\section{Materials and methods}

\subsection{Materials}

The stems and leaves of PCP were provided by Sichuan Traditional Chinese Medicine Decoction Co., Ltd. and appraised by Prof. Chunlei Fan, Zhejiang Chinese Medical University (Hangzhou, China). Escherichia coli ATCC35218, Staphylococcus aureus ATCC29213, S. aureus ATCC43300, and Enterococcus faecalis ATCC29212 were purchased from American Type Culture Collection (ATCC) (Manassas, VA, USA) and Bacillus subtilis CMCC1.1470 from the China Strain Preservation Center (Beijing, China). The human hepatocellular carcinoma cell line HepG2 (ATCC, Manassas, VA, USA) was provided by Associate Prof. Li Xu, Zhejiang Chinese Medical University.

\subsection{EAF preparation}

The stems and leaves of PCP were powdered with a herbgrinding machine (Wuyi Haina Electric Appliance Co., Ltd., Jinhua, Zhejiang, China) and sifted through an 80mesh screen. Powdered PCP stems and leaves were extracted twice with $70 \%$ ethanol for $1.5 \mathrm{~h}$. The crude extract was concentrated by rotary evaporation and successively extracted with petroleum and ethyl acetate. The ethyl acetate extracts of stems (SEAF) and of leaves (LEAF) were dried with rotary evaporation and weighed.

\subsection{Total flavonoids determination}

SEAF, LEAF, and rutin standards were dissolved in $70 \%$ ethanol and mixed successively with $1 \mathrm{~mL} 5 \%$ sodium nitrite solution, $1 \mathrm{~mL} 10 \%$ aluminum nitrate solution, and $10 \mathrm{~mL} 4 \%$ sodium hydroxide solution. Finally, $70 \%$ ethanol was added to adjust the volume of each mixture to $25 \mathrm{~mL}$. The absorbance $\left(A_{510}\right)$ of the mixtures was measured at $510 \mathrm{~nm}$ over $15 \mathrm{~min}$.

\subsection{Cell culture}

HepG2 cells were cultured in a 96-well plate containing $200 \mathrm{~mL}$ Dulbecco's Modified Eagle Medium (DMEM) with $10 \%(\mathrm{~V} / \mathrm{V})$ fetal bovine serum (containing $100 \mathrm{U} \cdot \mathrm{L}^{-1}$ penicillin and $100 \mathrm{mg} \cdot \mathrm{L}^{-1}$ streptomycin). The cell culture was grown in a $5 \% \mathrm{CO}_{2}$ incubator at $37^{\circ} \mathrm{C}$ with full humidity. To evaluate their cell protection activities, LEAF and SEAF solutions $\left(12.5,25,50\right.$, and $\left.100 \mu \mathrm{g} \cdot \mathrm{mL}^{-1}\right)$ were added to separate cell cultures. In addition, $0.4 \mathrm{mmol} \cdot \mathrm{L}^{-1}$ $\mathrm{H}_{2} \mathrm{O}_{2}, 0.5 \mathrm{mmol} \cdot \mathrm{L}^{-1}$ palmitate $(\mathrm{PA})$, and $0.5 \mathrm{mmol} \cdot \mathrm{L}^{-1}$ oleic acid (OA) were added to cell cultures to assess their ability to protect against OS, lipotoxicity, and TG accumulation.

\subsection{Apoptosis assessment}

Morphological changes of apoptosis could be observed under the microscope, using Hoechst 33342 (Thermo Scientific, Middletown, VA, USA) staining. The HepG2 cells were fixed with $4 \%$ paraformaldehyde in phosphate buffered saline for $10 \mathrm{~min}$. After staining with $5 \mathrm{mg} \cdot \mathrm{L}^{-1}$ Hoechst 33342 for $10 \mathrm{~min}$, the cells were visualized under a fluorescent microscope (Leica, Wetzlar, Germany).

\subsection{Triglycerides content assessment}

BODIPY (493/503) (Thermo Scientific, Middletown, VA, USA), 4,4-difluoro-1,3,5,7,8-pentamethyl-4-bora-3a,4adiaza-s-indacene, is a kind of lipophilic fluorochrome, which can stain triglyceride droplet in cells. The HepG2 cells were fixed with $4 \%$ paraformaldehyde in phosphate buffered saline for $10 \mathrm{~min}$. After staining with $1 \mathrm{mg} \cdot \mathrm{L}^{-1}$ BODIPY 493/503 for $30 \mathrm{~min}$, triglyceride droplet in cells were visualized under a fluorescent microscope (Leica, Wetzlar, Germany).

\subsection{Cell viability evaluation}

In this study, the cell viability was evaluated by measuring the amount of lactate dehydrogenase (LDH) released in the culture medium, using a LDH cytotoxicity assay kit (Thermo Scientific, Middletown, VA, USA) according to the manufacturer's instructions. The treated cell culture medium was transferred to a new plate and mixed with the reaction mixture from the kit. After $30 \mathrm{~min}$, the stop solution was added to stop the chromogenic reaction. LDH activity was then determined spectrophotometrically at $490 \mathrm{~nm}$.

\subsection{Triglyceride determination}

OA incubation induces TG accumulation in cells in vitro. In the current study, the concentration of TG in cells was determined by enzymatic colorimetry. The cultivated cells were lysed by lytic buffer at room temperature for $10 \mathrm{~min}$ followed by heating for $10 \mathrm{~min}$ at $70^{\circ} \mathrm{C}$. The cell debris and denatured proteins in the pyrolytic solution were discharged with centrifugation at $2000 \times g$ for $5 \mathrm{~min}$ at room temperature. TGs in this cell lytic solution were detected using a kit (Applygen Technologies Inc., Beijing, China) according to the manufacturer's instructions.

\subsection{Free radical scavenging activity quantitation}

DPPH (Sigma-Aldrich, Shanghai, China) was used as the free radical donor in this study. Each reaction mixture contained $50 \mu \mathrm{L}$ of the sample solution at various concentrations $(0,3.125,6.25,12.5,25,50$, and $100 \mu \mathrm{g} \cdot \mathrm{mL}^{-1}$ ) and $1 \mathrm{~mL}$ of $1 \mathrm{mmol} \cdot \mathrm{L}^{-1} \mathrm{DPPH}$ solution in 
ethanol. Each mixture was incubated for $30 \mathrm{~min}$ at $37^{\circ} \mathrm{C}$ and the absorbance was measured at $517 \mathrm{~nm}$. The percentage radical scavenging activity of each mixture was calculated in comparison with the $\mathrm{NC}$, using the following equation:

Scavenging activity $(\%)=\left[\left(A_{\text {control }}-A_{\text {sample }}\right) / A_{\text {control }}\right] \times 100$

The $\mathrm{EC}_{50}$ value of the compound was obtained with GraphPad prism.

\subsection{Antibacterial activity identification}

Antimicrobial activity was detected by using the Kirby Bauer agar diffusion method. Sterile 3MM Whatman filter paper discs (diameter $6 \mathrm{~mm}$ ) were saturated with either $10 \mathrm{mg} \cdot \mathrm{mL}^{-1}$ SEAF or LEAF $70 \%$ ethanol solution. $70 \%$ ethanol was used as a negative control. An air-dried filter paper disc was placed on each LB agar plate containing different test strains of bacteria $\left(10^{7}-10^{8} \mathrm{cfu} \cdot \mathrm{mL}^{-1}\right)$. Each test solution contained at least four repeats. The agar plates were placed in a $37^{\circ} \mathrm{C}$ incubator and the diameter of each inhibitory zone was measured after $20 \mathrm{~h}$.

\subsection{Statistical analysis}

All experiments were repeated at least three times. The data from each group were expressed as mean \pm standard deviation. Differences between the groups were determined using the Student's $t$-test, analyzed with SPSS 22.0 software. Differences were significant at the $P<0.05$ level.

\section{Results}

\subsection{Preparation of EAF and flavonoid concentration}

The extraction rates $(\mathrm{g} / \mathrm{g})$ of SEAF and LEAF were $3.55 \% \pm 0.24 \%$ and $8.73 \% \pm 2.31 \%$, respectively. Flavonoid content was calculated according to the standard curve of rutin. The total flavonoid concentration $(\mathrm{g} / \mathrm{g})$ in SEAF and LEAF was $16.05 \% \pm 1.60 \%$ and $39.27 \% \pm$ $6.54 \%$, respectively.

\subsection{Demonstration of triglyceride accumulation and lipotoxicity attenuation inhibitory effects}

OA, a monounsaturated fatty acid, promoted the formation of triglyceride-enriched lipid droplets in HepG2 cells which could be stained by fluorochrome BODIPY and observed under the microscope (Fig. 1(a)). The total TG accumulation in cells from the treatment groups was calculated and compared with that of the control group (C, untreated), as shown in Fig. 1(b). In this experiment, (a)

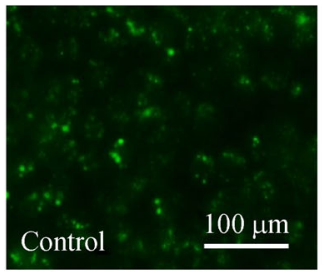

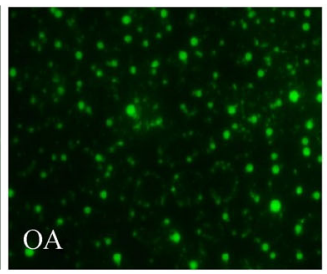

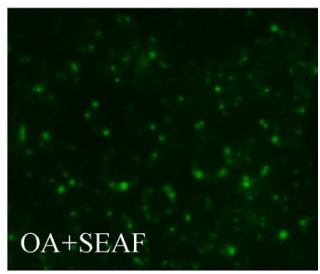

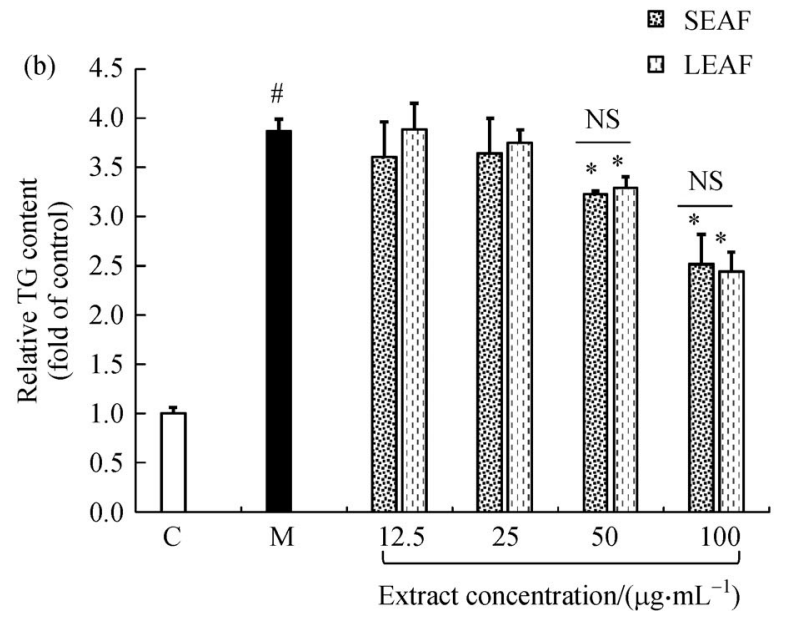

Fig. 1 Cell protective efficiency of SEAF and LEAF against OA induced lipid accumulation. (a) The images of BODIPY stained HepG2 cells; (b) the relative TG content. Control (C) and model (M) groups are untreated and $0.5 \mathrm{mmol} \cdot \mathrm{L}^{-1} \mathrm{OA}$ treated HepG2 cell groups, respectively. The others are sample groups that $12.5,25,50,100 \mu \mathrm{g} \cdot \mathrm{mL}^{-1} \mathrm{SEAF}$ and LEAF protected HepG2 cell groups, against $0.5 \mathrm{mmol} \cdot \mathrm{L}^{-1} \mathrm{OA}$ treatment. \# indicates significant difference between the $\mathrm{C}$ and $\mathrm{M}$ groups; * indicates significant difference between the sample and M groups; NS indicates nonsignificant difference between the same concentrations of SEAF and LEAF $(P<0.05)$. 
the accumulated TG in the model group $\left(\mathrm{M}, 0.5 \mathrm{mmol} \cdot \mathrm{L}^{-1}\right.$ OA treated) increased to $3.87 \pm 0.12$. The inhibitory effects of LEAF and SEAF $\left(>50 \mu \mathrm{g} \cdot \mathrm{mL}^{-1}\right)$ were similar. In detail, the concentration of TG in the $12.5,25,50$, and $100 \mu \mathrm{g} \cdot \mathrm{mL}^{-1}$ LEAF groups was $3.61 \pm 0.35,3.64 \pm 0.36$, $3.22 \pm 0.04$, and $2.52 \pm 0.30$, respectively, whereas that in the $12.5,25,50$, and $100 \mu \mathrm{g} \cdot \mathrm{mL}^{-1}$ SEAF groups was $3.89 \pm 0.26,3.75 \pm 0.13,3.29 \pm 0.114$, and $2.44 \pm 0.19$, respectively.

The excess free fatty acids, such as PA, have a toxicity effect and reduce cell viability. In the model group (M), which was treated by $0.5 \mathrm{mmol} \cdot \mathrm{L}^{-1} \mathrm{PA}$, the relative released LDH increased by $7.97 \pm 0.19$ folds. The results showed pretreatment with SEAF and LEAF attenuated the lipotoxicity of PA in a dose dependent manner (Fig. 2; Table 1).

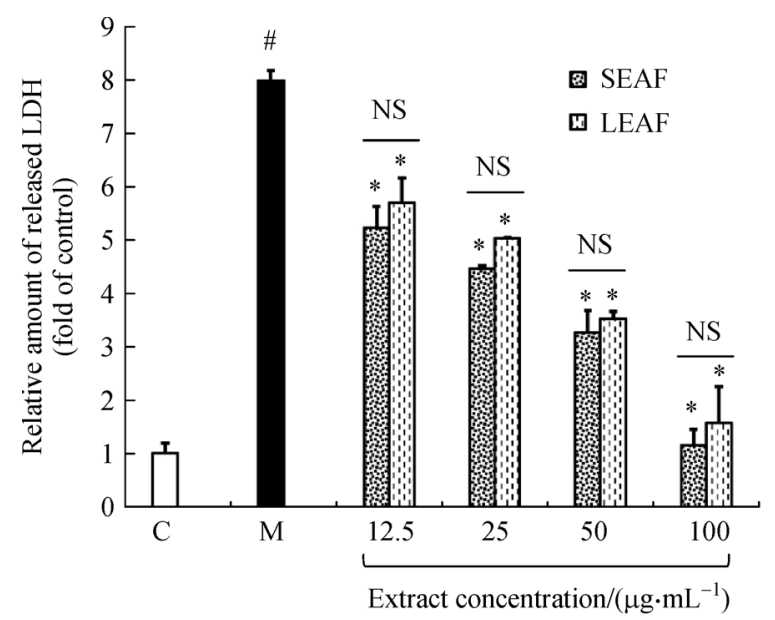

Fig. 2 Lipotoxicity attenuation efficiency of SEAF and LEAF against PA induced cell injury, measured as the relative amounts of released LDH. Control (C) and model (M) groups are untreated and $0.5 \mathrm{mmol} \cdot \mathrm{L}^{-1} \mathrm{PA}$ treated HepG2 cell groups, respectively. The others are sample groups that $12.5,25,50,100 \mu \mathrm{g} \cdot \mathrm{mL}^{-1}$ SEAF and LEAF protected HepG2 cell groups, against $0.5 \mathrm{mmol} \cdot \mathrm{L}^{-1} \mathrm{PA}$ treatment. \# indicates significant difference between the $\mathrm{C}$ group and $\mathrm{M}$ group; * indicates significant difference between the sample group and $\mathrm{M}$ group; $\mathrm{NS}$ indicates nonsignificant difference between the same concentrations of SEAF and LEAF $(P<0.05)$.

Lipid accumulation is a regular feature of dysfunctional hepatic cell. This result explored the protective activities of LEAF and SEAF against lipid accumulation induced by $\mathrm{OA}$ and lipotoxicity induced by PA. There were no significant differences in the activities between SEAF and LEAF.

\subsection{Comparative evaluation of antioxidation efficiency}

OS, which leads to lipid accumulation and NAFLD development, occurs as a result of excessive reactive oxygen species. The anti-oxidation efficiency of LEAF and SEAF was evaluated with DPPH free radicals scavenging (Fig. 3) and $\mathrm{H}_{2} \mathrm{O}_{2}$ treated HepG2 cell assay (Fig. 4), respectively. Scavenging of DPPH free radical is the basis of a common antioxidant assay. DPPH free radicals incubated with various dosages of LEAF or SEAF for $30 \mathrm{~min}$ at $37^{\circ} \mathrm{C}$ were eliminated in a dose-dependent manner (Fig. 3). The half maximum scavenging activity $\left(\mathrm{EC}_{50}\right)$ of $\mathrm{EAF}$ from stems and leaves was 7.30 and $12.72 \mu \mathrm{g} \cdot \mathrm{mL}^{-1}$, respectively.

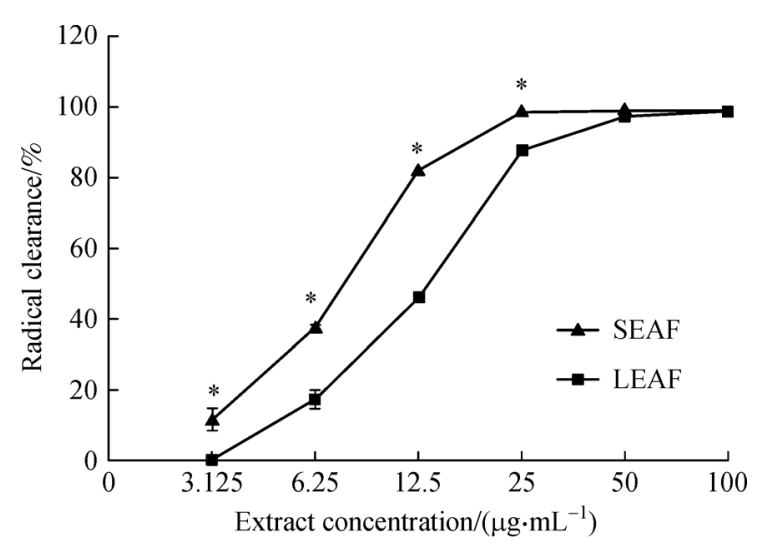

Fig. 3 DPPH free radical clearance activities of SEAF and LEAF. * indicates significant difference between SEAF and LEAF $(P<0.05)$.

Based on the results of the free radical scavenging assessment, the protective effects of SEAF and LEAF against $\mathrm{H}_{2} \mathrm{O}_{2}$ treatment on HepG2 cells were evaluated by comparing the concentration of $\mathrm{LDH}$ in the different culture media. In a biological context, $\mathrm{H}_{2} \mathrm{O}_{2}$ can be partially reduced to hydroxyl radical which induces apoptosis. The concentration of LDH released by cells is proportional to the number of apoptotic cells. The apoptotic cells could be stained by Hoechst and observed under the microscope (Fig. 4(a)). The relative released LDH was calculated from the $A_{490}$ and compared with that of the control group (C). After $\mathrm{H}_{2} \mathrm{O}_{2}$ treatment, the released

Table 1 Relative amount of released LDH in PA treated HepG2 assays protected by different concentrations of EAFs $\left(\mu \mathrm{g} \cdot \mathrm{mL}^{-1}\right)$

\begin{tabular}{lccccc}
\hline \multirow{2}{*}{ Sample } & \multicolumn{5}{c}{ Relative amount of released LDH (fold of control) } \\
\cline { 2 - 6 } & 0 & 12.5 & 25 & 50 & 100 \\
\hline SEAF & $7.97 \pm 0.19$ & $5.22 \pm 0.39$ & $4.46 \pm 0.04$ & $3.26 \pm 0.41$ & $1.15 \pm 0.30$ \\
LEAF & $7.97 \pm 0.19$ & $5.69 \pm 0.47$ & $5.02 \pm 0.02$ & $3.51 \pm 0.15$ & $1.56 \pm 0.68$ \\
\hline
\end{tabular}


LDH in the model group (M) increased significantly. In comparison with the $\mathrm{M}$, more than $25 \mu \mathrm{g} \cdot \mathrm{mL}^{-1} \mathrm{SEAF}$ and LEAF showed remarkable protective activities (Fig. 4(b); Table 2). At the same concentration, LEAF activity was significantly higher activity than that of SEAF, suggesting that the anti-oxidation properties of LEAF and SEAF were not identical.

\subsection{Identification of bacteriostatic activity}

The released of LPS by intestinal flora is one of major factors which lead to dysfunction of hepatic cells. Therefore inhibiting overgrowth of intestinal microorganisms could influence the LPS induced cell injury. In this work, the bacteriostatic activities of SEAF and LEAF were expressed as inhibition zone diameter (IZD) at a concentration of $10 \mathrm{mg} \cdot \mathrm{mL}^{-1}$ (Table 3 ). The results indicated that both LEAF and SEAF of PCP have anti-bacteria activities. Based on the IZD, the bacterial susceptibility, from strong to weak, was $E$. coli $>$ B. subtilis $>S$. aureus ATCC43300 $>S$. aureus ATCC29213 $>E$. faecalis for SEAF, and $S$. aureus ATCC $43300>$ B. subtilis $>$ E. coli $>$ S. aureus ATCC292 $13>$ E. faecalis for LEAF.

\section{Discussion}

EAF have been reported to have the strongest activity of the fractionated extracts of $\mathrm{PCP}^{[18]}$. In this study we prepared the EAF from leaves and stems of PCP and the flavonoid concentration in LEAF and SEAF were

Table 2 Relative amount of released LDH in $\mathrm{H}_{2} \mathrm{O}_{2}$ treated HepG2 assays protected by different concentrations of EAFs $\left(\mu \mathrm{g} \cdot \mathrm{mL}^{-1}\right)$

\begin{tabular}{lcccc}
\hline Sample & \multicolumn{4}{c}{ Relative amount of released LDH (fold of control) } \\
\cline { 2 - 5 } & 0 & 12.5 & 25 & 50 \\
\hline SEAF & $4.20 \pm 0.08$ & $4.12 \pm 0.23$ & $3.70 \pm 0.06$ & $2.68 \pm 0.14$ \\
LEAF & $4.20 \pm 0.08$ & $4.20 \pm 0.09$ & $2.90 \pm 0.03$ & $1.90 \pm 0.14$ \\
\hline
\end{tabular}

(a)
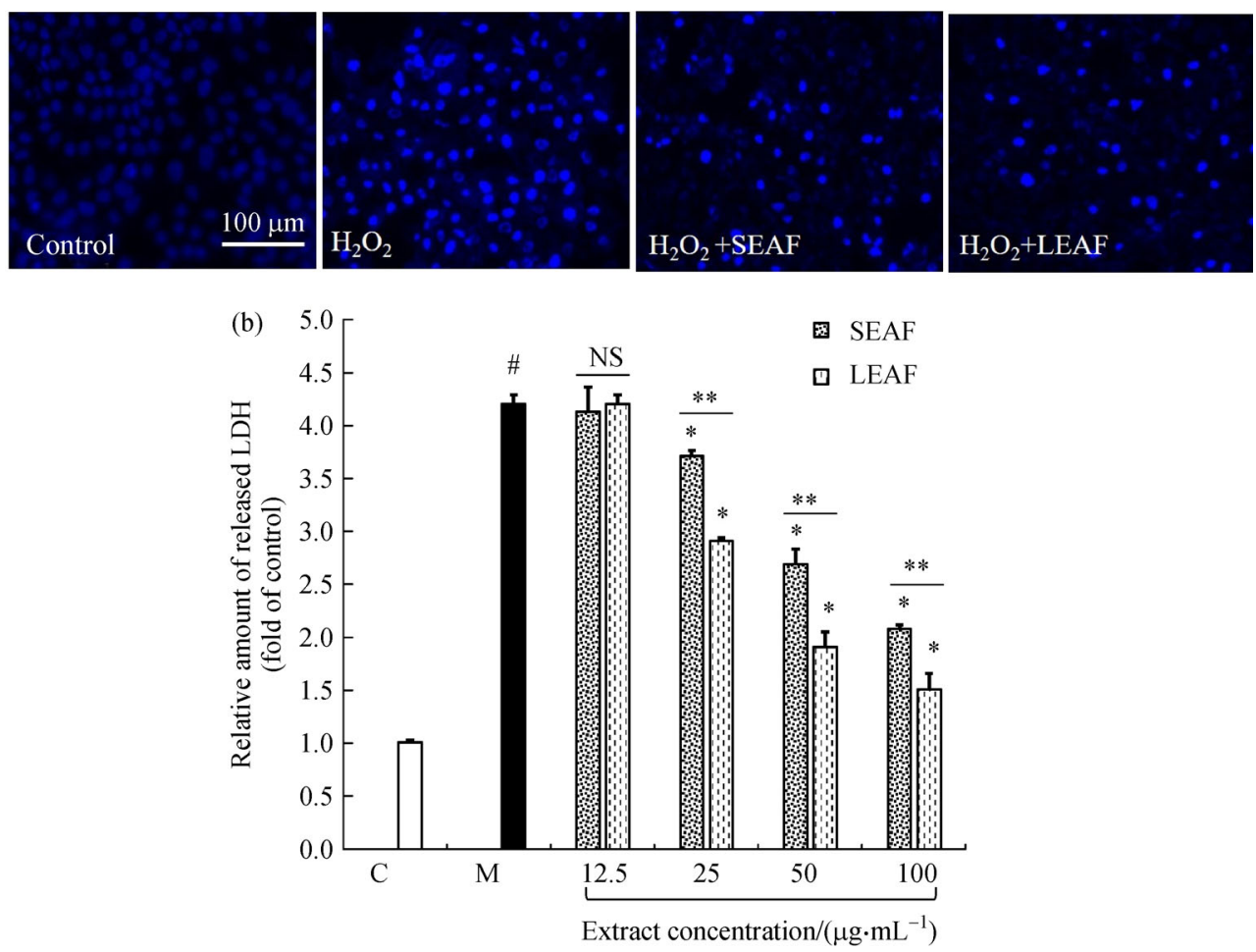

Fig. 4 Cell protective efficiency of SEAF and LEAF against $\mathrm{H}_{2} \mathrm{O}_{2}$ oxidative damage. (a) The images of Hoechst stained HepG2 cells; (b) the relative amounts of released LDH. Control (C) and model (M) groups are untreated and $0.4 \mathrm{mmol} \cdot \mathrm{L}^{-1} \mathrm{H}_{2} \mathrm{O}_{2}$ treated $\mathrm{HepG} 2$ cells, respectively. The others are sample groups that $12.5,25,50,100 \mu \mathrm{g} \cdot \mathrm{mL}^{-1} \mathrm{SEAF}$ and LEAF protected HepG2 cell groups, against $0.4 \mathrm{mmol} \cdot \mathrm{L}^{-1} \mathrm{H}_{2} \mathrm{O}_{2}$ treatment. \# indicates significant differences between the $\mathrm{M}$ and the $\mathrm{C}$; * indicates significant differences between the EAF sample groups and $\mathrm{M}$ group; $\underline{\mathrm{NS}}$ and $* *$ indicate nonsignificant or significant differences, respectively, between the same concentrations of SEAF and LEAF $(P<0.05)$. 
Table 3 Inhibitory zone diameter (mean \pm SD) of SEAF and LEAF against different bacterial strains

\begin{tabular}{lccccc}
\hline \multirow{2}{*}{ Sample } & \multicolumn{5}{c}{ Inhibitory zone diameter/mm } \\
\cline { 2 - 6 } & $\begin{array}{c}\text { Escherichia coli } \\
\text { ATCC35218 }\end{array}$ & $\begin{array}{c}\text { Bacillus subtilis } \\
\text { CMCC1.1470 }\end{array}$ & $\begin{array}{c}\text { Enterococcus faecalis } \\
\text { ATCC29212 }\end{array}$ & $\begin{array}{c}\text { Staphylococcus aureus } \\
\text { ATCC29213 }\end{array}$ & $\begin{array}{c}\text { Staphylococcus aureus } \\
\text { ATCC43300 }\end{array}$ \\
\hline SEAF & $13.50 \pm 0.71$ & $10.83 \pm 0.58$ & $9.33 \pm 0.58$ & $10.33 \pm 0.58$ & $10.75 \pm 0.35$ \\
LEAF & $10.50 \pm 0.41$ & $10.83 \pm 0.68$ & $9.32 \pm 0.68$ & $9.53 \pm 0.58$ & $11.25 \pm 0.35$ \\
\hline
\end{tabular}

quantitated. The extraction ratio of EAF and the flavonoid content of leaves were more than twice that of those from the stems. Sun et al. ${ }^{[25]}$ studied the total flavonoid content in the leaves of PCP at different growth stages. They found that the flavonoid content in the leaves was $4.3 \%-4.5 \%$ before flowering, which was higher than at other growth stages. Obviously, leaves gathered before flowering are a better source of PCP flavonoid preparations than stems.

To date, there have been few studies on the cell protection activities of PCP extracts against lipid accumulation and lipotoxicity. It was reported that Gansu granules (made from an extract of PCP) improved lipid metabolism, lowered blood sugar and reduced bodyweight ${ }^{[17]}$. In 2014, Xiao et al. ${ }^{[26]}$ reported that PCP extract can reduce the concentration of TG in the serum and liver of a rat model of non-alcoholic fatty liver disease and alleviated fatty lesions in liver tissue. Those studies were carried out in clinic or with an animal model, in vivo. Our results validated these previous studies with cell assay, in vitro. ROS, a key factor, contributes to lipid metabolic disturbance in hepatocyte, and in a lipid-rich environment causes lipid accumulation $^{[5,6]}$. So, we evaluated the antioxidant activities of both LEAF and SEAF with two kinds of assays. By DPPH assay, the free radical scavenging activity of LEAF $\left(\mathrm{EC}_{50}=\right.$ $\left.12.72 \mu \mathrm{g} \cdot \mathrm{mL}^{-1}\right)$ was lower than that of SEAF $\left(\mathrm{EC}_{50}=\right.$ $7.3 \mu \mathrm{g} \cdot \mathrm{mL}^{-1}$ ). By contrast, the $\mathrm{H}_{2} \mathrm{O}_{2}$ oxidant protection activity of LEAF (at concentrations $>25 \mu \mathrm{g} \cdot \mathrm{mL}^{-1}$ ) was significantly higher than that of SEAF $(P<0.05)$. The differences in activity between LEAF and SEAF could result from variations in their chemical composition, as reported previously ${ }^{[27]}$. Tuo et al ${ }^{[28]}$ reported three more characteristic peaks in leaves than in stems, based on high performance liquid chromatography. Unfortunately, no studies have been conducted to identify these compounds. Whereas DPPH comprises stable free radical molecules, hydrogen peroxide $\left(\mathrm{H}_{2} \mathrm{O}_{2}\right)$ is one of ROS which is generated as a short-lived product in biochemical processes, such as $\beta$-oxidation of long chain fatty acids ${ }^{[29]}$. And ROS appears to be a feature of liver diseases ${ }^{[30,31]}$. Therefore, leaves, not stems, of PCP are an ideal material for use as a liver diseases treatment.

Flavonoids are common active components in herbs, which show a variety of biological activities, including not only antioxidation but also bacteriostatic effects ${ }^{[32]}$. Previous studies reported that quercetin and pinocembrin-7-O- $\beta$-glucoside ${ }^{[33-35]}$ are abundant in PCP. Both compounds showed antibacterial activity ${ }^{[36,37]}$. Previous studies also reported that the EAF of PCP has similar bacteriostatic activity against Pseudomonas aeruginosa $\left(\mathrm{G}^{-}\right)$and $S$. aureus $\left(\mathrm{G}^{+}\right)^{[20,21]}$. The bacteriostatic activity of the two fractions were identified in the agar diffusion experiments with E. coli, B. subtilis, E. faecalis and two $S$. aureus strains, separately. There was no significant difference in the IZD obtained with the tested strains using SEAF and LEAF, apart from a higher IZD of SEAF on the E. coli plate. Although the flavonoid content of LEAF was more than twice that of SEAF, there was no significant difference in antibacterial activity between SEAF and LEAF. Thus, we hypothesize that SEAF and LEAF have nonspecific antibacterial activity and that the content of active compounds in leaves is not significantly different from that in stems. Our results suggest that this nonspecific antibacterial activity of EAF could reduce internal flora and prevent LPS induced liver damage by an indirect effect. This could be tested with current cell or animal models.

\section{Conclusions}

This study suggested that both LEAF and SEAF can prevent lipid accumulation in hepatic cells by their antioxidation activity. In addition, PCP may also influence the LPS induced liver injury by its bacteriostatic activities. Leaves of PCP were found to produce an EAF with a higher flavonoid content and present significant higher capability against hydroxyl radicals, than stems. Thus, we suggest that leaves extracts, rather than those from the stems, should be explored further for clinical use.

Acknowledgements This study was supported by National Natural Science Foundation of China (81473393, 31600003).

Compliance with ethics guidelines Zhaolei Wang, Kai Jiang, Qinchao Ding, Shujun Liu, Xiaobing Dou, and Bin Ding declare that they have no conflicts of interest or financial conflicts to disclose.

This article does not contain any studies with human or animal subjects performed by any of the authors.

\section{References}

1. Schattenberg J M, Bergheim I. Nutritional intake and the risk for non-alcoholic fatty liver disease (NAFLD). Nutrients, 2019, 11(3): 588-592 
2. Neuschwander-Tetri B A. Hepatic lipotoxicity and the pathogenesis of nonalcoholic steatohepatitis: the central role of nontriglyceride fatty acid metabolites. Hepatology, 2010, 52(2): 774-788

3. Malhi H, Gores G J. Molecular mechanisms of lipotoxicity in nonalcoholic fatty liver disease. Seminars in Liver Disease, 2008, 28 (4): 360-369

4. D'Adamo E, Santoro N, Caprio S. Metabolic syndrome in pediatrics: old concepts revised, new concepts discussed. Pediatric Clinics of North America, 2011, 58(5): 1241-1255

5. Cichoż-Lach H, Michalak A. Oxidative stress as a crucial factor in liver diseases. World Journal of Gastroenterology, 2014, 20(25): 8082-8091

6. Jadeja R N, Devkar R V, Nammi S. Oxidative stress in liver diseases: pathogenesis, prevention, and therapeutics. Oxidative Medicine and Cellular Longevity, 2017, 2017: 8341286

7. Milosevic I, Vujovic A, Barac A, Djelic M, Korac M, Radovanovic Spurnic A, Gmizic I, Stevanovic O, Djordjevic V, Lekic N, Russo E, Amedei A. Gut-liver axis, gut microbiota, and its modulation in the management of liver diseases: a review of the literature. International Journal of Molecular Sciences, 2019, 20(2): 395

8. Fitriakusumah Y, Lesmana C R A, Bastian W P, Jasirwan C O M, Hasan I, Simadibrata M, Kurniawan J, Sulaiman A S, Gani R A. The role of small intestinal bacterial overgrowth (SIBO) in non-alcoholic fatty liver disease (NAFLD) patients evaluated using controlled attenuation parameter (CAP) transient elastography (TE): a tertiary referral center experience. BMC Gastroenterology, 2019, 19(1): 43

9. Zhang F M, Lu X, Zhang Y T, Zhang D Y, Ran X, Zeng F J. Research on edible proportion of Penthorum chinense Pursh through population survey in Gulin. Food Industries, 2016, 37 (11): 232-236 (in Chinese)

10. Wang A, Lin L, Wang Y. Traditional Chinese herbal medicine Penthorum chinense Pursh. A phytochemical and pharmacological review. American Journal of Chinese Medicine, 2015, 43(4): 601620

11. Chen Y J. A study on effect of "Penthorum chinense Pursh" on liver fibrosis due to chronic hepatitis B and HSC. Guangzhou University of Chinese Medicine, 2008 (in Chinese)

12. Yu L, Tang Y, Zhang R, Wu B. Systematic evaluation on Gansu granules for treating chronic hepatitis B. China Pharmaceuticals, 2012, 21: 20-22 (in Chinese)

13. Yu W J, Wang S Q, Gen C E, Yin X F, Shi H J. 86 clinic cases of hepatitis B report: Gansu granule combined with liver disease therapeutic instrument treatment. Liaoning Journal of Traditional Chinese Medicine, 2007, 34(2): 173-174 (in Chinese)

14. Wang J B, Li Z, Zhao Y H. Clinical observation of Ganhuangcao compound treating patients with alcoholic fatty liver disease. Chinese Journal of Experimental Traditional Medical Formulae, 2016, 22(13): 156-160 (in Chinese)

15. Zhang C F, Li Z H, Pan X F, Xue B Y, Jin X J. Clinical observation of Gansu granule in the treatment of non-alcoholic steatohepatitis. Chinese Journal of Pharmacoepidemiology, 2007, 16(1): 5-7 (in Chinese)

16. Zhu B Y, Tang G M. Clinical observation on adefovir dipivoxil combined with Gansu capsule for active liver cirrhosis. Chinese Journal of Clinical Rational Drug Use, 2009, 2(11): 17 (in Chinese) 17. Huang D, Jiang Y, Chen W, Yao F, Huang G, Sun L. Evaluation of hypoglycemic effects of polyphenols and extracts from Penthorum chinense. Journal of Ethnopharmacology, 2015, 163: 256-263

18. Yu F X, Chen M X, Cheng Q, Chen T, Fu L, Ding C B. Classified extraction and activity of total flavonoids from Penthorum chinense Purse. Natural Product Research and Development, 2017, 6(29): 976-982 (in Chinese)

19. Guo W W, Wang X, Chen X Q, Ba Y Y, Zhang N, Xu R R, Zhao W W, Wu X. Flavonones from Penthorum chinense ameliorate hepatic steatosis by activating the SIRT1/AMPK Pathway in HepG2 Cells. International Journal of Molecular Sciences, 2018, 19(9): 2555

20. Lei J, Xiao M, Zhu R, Xia J R, Yang Z Q. Preliminary antimicrobial activity of different solvent extracts from Phethorum chinense Pursh. Asia-Pacific Traditional Medicine, 2012, 8(8): 29-30 (in Chinese)

21. Shu G, Cao H, Lin J C, Lv C, Zhang W. Study on the in vitro antibacterial effect of Penthorum chinense extracts combined with antibiotics against Staphylococcus aureus. Journal of Anhui Agricultural Sciences, 2012, 40(2):837-863, 926 (in Chinese)

22. He X H, Xu L, Tan M L, Du F L, Zeng J G. DPPH radical scavenging effect of Penthorum chinense Pursh extract. Lishizhen Medicine and Materia Medical Research, 2009, 20(8): 1924-1926 (in Chinese)

23. He L, Zhang S, Luo C, Sun Y, Lu Q, Huang L, Chen F, Tang L. Functional teas from the stems of Penthorum chinense Pursh: phenolic constituents, antioxidant and hepatoprotective activity. Plant Foods for Human Nutrition, 2019, 74(1): 83-90

24. Zhou Y T, Zhao C W. Popularity investigation and expanding strategy of genuine medicinal materials Penthorum chinense Pursh in Luzhou. Journal of Anhui Agricultural Sciences, 2016, 44(14): 172-174 (in Chinese)

25. Sun P, Tong W, Yang X, Huang L L, Hu S Q. Study on variation of plant weight and active component contents in herba penthori at different growth stages. Southwest China Journal of Agricultural Sciences, 2013, 26(6): 2666-2668 (in Chinese)

26. Xiao L P, Song Y Y, Zhou Y X, Liu J L, He S, Zhang D Y, Xie X F, Peng C. Experiment research about resistant effects of Penthorum chinese on nonalcoholic fatty fiver. Chinese Journal of Experimental Traditional Medical Formulae, 2014, 20(10): 125-129 (in Chinese)

27. Han W, Zhang H, Zhang Z J, Li H. Comparison of HPLC characteristic fingerprints of stems and leaves of Penthorum chinense. Journal of Chinese Medicinal Materials, 2013, 36(3): 387-391 (in Chinese)

28. Tuo Y L, Jin L, Zhang X. Comparison of HPLC fingerprint analysis of Flos, Caulis and Folium from Penthorum chinense. Chinese Journal of Experimental Traditional Medical Formulae, 2015, 21 (15): 61-64 (in Chinese)

29. Gabaldón T. Peroxisome diversity and evolution. Philosophical Transactions of the Royal Society of London. Series B: Biological Sciences, 2010, 365(1541): 765-773

30. Chen X, Xue H, Fang W, Chen K, Chen S, Yang W, Shen T, Chen $\mathrm{X}$, Zhang $\mathrm{P}$, Ling W. Adropin protects against liver injury in nonalcoholic steatohepatitis via the Nrf2 mediated antioxidant capacity. Redox Biology, 2019, 21: 101068

31. Nagappan A, Jung D Y, Kim J H, Lee H, Jung M H. Gomisin N alleviates ethanol-induced liver injury through ameliorating lipid 
metabolism and oxidative stress. International Journal of Molecular Sciences, 2018, 19(9): 2601

32. Kumar S, Pandey A K. Chemistry and biological activities of flavonoids: an overview. The Scientific World Journal, 2013, 2013: 162750

33. He X H, Wang X S, Zen J G. Determination of quercetin, quercetol and pinocembrin-7-O-glucoside in Penthorum chinense Pursh by HPLC. Chinese Traditional and Herbal Drugs, 2009, 40(6): 981983 (in Chinese)

34. Guo W, Jiang Y, Chen X, Yu P, Wang M, Wu X, Zhang D. Identification and quantitation of major phenolic compounds from Penthorum chinense Pursh by HPLC with tandem mass spectrometry and HPLC with diode array detection. Journal of Separation
Science, 2015, 38(16): 2789-2796

35. Sun Z L, Zhang Y Z, Zhang F, Zhang J W, Zheng G C, Tan L, Wang C Z, Zhou L D, Zhang Q H, Yuan C S. Quality assessment of Penthorum chinense Pursh through multicomponent qualification and fingerprint, chemometric, and antihepatocarcinoma analyses. Food \& Function, 2018, 9(7): 3807-3814

36. Wang S, Yao J, Zhou B, Yang J, Chaudry M T, Wang M, Xiao F, Li $\mathrm{Y}$, Yin W. Bacteriostatic effect of quercetin as an antibiotic alternative in vivo and its antibacterial mechanism in vitro. Journal of Food Protection, 2018, 81(1): 68-78

37. Hu F L. Advances on the chemical composition, quality control and biology activity of propolis. Journal of Economic Animal, 2017, 21 (4): 187-196, 200 (in Chinese) 